\title{
Allelic Variation of the Tas1r3 Taste Receptor Gene Selectively Affects Behavioral and Neural Taste Responses to Sweeteners in the $\mathrm{F}_{2}$ Hybrids between $\mathrm{C} 57 \mathrm{BL} / 6 \mathrm{ByJ}$ and 129P3/J Mice
}

\author{
Masashi Inoue, ${ }^{1}$ Danielle R. Reed, ${ }^{2}$ Xia Li, ${ }^{2}$ Michael G. Tordoff, ${ }^{2}$ Gary K. Beauchamp, ${ }^{2,3}$ and Alexander A. Bachmanov ${ }^{2}$ \\ ${ }^{1}$ Laboratory of Cellular Neurobiology, School of Life Science, Tokyo University of Pharmacy and Life Science, Hachioji, Tokyo 192-0392, Japan, ${ }^{2}$ Monell \\ Chemical Senses Center, Philadelphia, Pennsylvania 19104, and ${ }^{3}$ Department of Psychology and School of Veterinary Medicine, University of Pennsylvania, \\ Philadelphia, Pennsylvania 19104
}

\begin{abstract}
Recent studies have shown that the T1R3 receptor protein encoded by the Tas $1 r 3$ gene is involved in transduction of sweet taste. To assess ligand specificity of the T1R3 receptor, we analyzed the association of Tas $1 r 3$ allelic variants with taste responses in mice. In the $\mathrm{F}_{2}$ hybrids between the C57BL/6ByJ (B6) and 129P3/J (129) inbred mouse strains, we determined genotypes of markers on chromosome 4, where Tas $1 r 3$ resides, measured consumption of taste solutions presented in two-bottle preference tests, and recorded integrated responses of the chorda tympani gustatory nerve to lingual application of taste stimuli. For intakes and preferences, significant linkages to Tas $1 r 3$ were found for the sweeteners sucrose, saccharin, and D-phenylalanine but not glycine. For chorda tympani responses, significant linkages to Tas1r3 were found for the sweeteners sucrose, saccharin, D-phenylalanine, D-tryptophan, and SC-45647 but not glycine, L-proline, L-alanine, or L-glutamine. No linkages to distal chromosome 4 were detected for behavioral or neural responses to non-sweet quinine, citric acid, $\mathrm{HCl}, \mathrm{NaCl}, \mathrm{KCl}$, monosodium glutamate, inosine $5^{\prime}$-monophosphate, or ammonium glutamate. These results demonstrate that allelic variation of the Tas1r3 gene affects gustatory neural and behavioral responses to some, but not all, sweeteners. This study describes the range of ligand sensitivity of the T1R3 receptor using an in vivo approach and, to our knowledge, is the first genetic mapping study of activity in gustatory nerves.
\end{abstract}

Key words: taste; sweet; preference; consumption; chorda tympani nerve; electrophysiology; genetics

\section{Introduction}

Sugars, and a wide range of other chemicals (referred to here as sweeteners), evoke the sensation of sweetness in humans and are palatable to many other animals. Sweetness perception is initiated in taste receptor cells in the taste buds of the oral cavity and has been proposed to involve a dimer of the T1R2 and T1R3 receptor proteins (Nelson et al., 2001, 2002; Li et al., 2002a). The Tas1r3 gene encoding the T1R3 protein was discovered as a result of positional cloning of the mouse saccharin preference ( $\mathrm{Sac}$ ) locus on chromosome 4 (Bachmanov et al., 2001b). Allelic variation of the Sac/Tas1r3 gene in inbred, transgenic, and knock-out mouse strains affects behavioral and neural taste responses to several sweeteners (Lush, 1989; Lush et al., 1995; Bachmanov et al., 1997; Blizard et al., 1999; Li et al., 2001; Nelson et al., 2001; Damak et al., 2003; Zhao et al., 2003; Reed et al., 2004), suggesting that these compounds evoke the sweet taste sensation via a com-

Received Sept. 30, 2003; revised Jan. 6, 2004; accepted Jan. 7, 2004.

This work was supported by National Institutes of Health Grants DC00882 (G.K.B.); DC03509, DC04188, and DK55853 (D.R.R.); AA11028 (M.G.T.); and DC03853 (A.A.B.). We thank Dr. Grant DuBois for the gift of SC-45647.

Correspondence should be addressed to Dr. Gary K. Beauchamp, Monell Chemical Senses Center, 3500 Market Street, Philadelphia, PA 19104. E-mail: beauchamp@monell.org.

DOI:10.1523/JNEUROSCI.4439-03.2004

Copyright $\odot 2004$ Society for Neuroscience $\quad$ 0270-6474/04/242296-08\$15.00/0 mon receptor, T1R3. Because there is only limited information on the specificity of Tas1r3 effects on taste responses, we undertook this study to assess how the Tas1r3 genotype affects behavioral and neural gustatory responses to a wide range of sweeteners.

In this study, we used $\mathrm{F}_{2}$ hybrids of mice from the C57BL/6ByJ (B6) and 129P3/J (129) inbred strains, which carry different alleles of the Tas1r3 gene (Bachmanov et al., 2001b; Reed et al., 2004). The Tas1r3 genotype of each $\mathrm{F}_{2}$ mouse was determined, and its association with neural and behavioral taste responses was analyzed. We examined integrated responses to lingual application of taste stimuli in the chorda tympani gustatory nerve, which in mice robustly responds to sweeteners (Ninomiya et al., 1993; Inoue et al., 2001a; Damak et al., 2003; Danilova and Hellekant, 2003), and consumption of taste solutions given to mice in twobottle preference tests. This allowed us to assess how allelic variation in the taste receptor affects afferent sensory input and behavioral output in response to sweeteners in the whole animal. The neural and behavioral responses of mice from the parental B6 and 129 strains to a wide range of sweeteners have been characterized in our previous studies (Bachmanov et al., 1996a, 2001a; Inoue et al., 2001a). Here, we selected for testing in the B6 $\times 129$ $\mathrm{F}_{2}$ mice sweeteners that (1) evoke different responses in the two 
parental strains, and (2) represent chemically and physiologically distinct stimuli, including sugars, amino acids, and artificial sweeteners. Besides sweeteners, we also included taste stimuli representing other taste qualities: bitter, sour, salty, and umami (a fifth taste quality exemplified by the taste of glutamate) (Yamamoto et al., 1991). The umami-tasting compounds were of particular interest because a combination of the T1R3 and T1R1 receptors may transduce umami taste (Li et al., 2002a).

\section{Materials and Methods}

Animals. Mice from the C57BL/6ByJ (B6) and 129P3/J (129) inbred strains were obtained from The Jackson Laboratory (Bar Harbor, ME) and were intercrossed to produce $\mathrm{F}_{1}$ and $\mathrm{F}_{2}$ hybrids. Pups were weaned at $21-30 \mathrm{~d}$ of age and reared in groups of the same gender (in most cases, four to six mice per cage, but never more than six in one cage). The mice were housed in a temperature-controlled vivarium at $23^{\circ} \mathrm{C}$ on a $12 \mathrm{hr}$ light/dark cycle and had ad libitum access to water and Teklad Rodent Diet 8604. During the two-bottle tests, the mice were housed individually.

Two groups of $\mathrm{F}_{2}$ mice were bred and phenotyped in separate experiments. Group 1 consisted of 171 male mice obtained from two types of reciprocal crosses: $(129 q \times \mathrm{B} 6 \hat{\jmath}) \mathrm{F}_{1}$ 우 $\times(129 q \times \mathrm{B} 6 \hat{\sigma}) \mathrm{F}_{1} \hat{0}(80$ males $)$ and $(\mathrm{B} 6 q \times 129 \hat{\sigma}) \mathrm{F}_{1} q \times(\mathrm{B} 6 q \times 129 \hat{\jmath}) \mathrm{F}_{1} \hat{\jmath}(91$ males $)$. Group 2 consisted of 456 (228 females and 228 males) $\mathrm{F}_{2}$ mice obtained from three types of reciprocal crosses: $(129 q \times \mathrm{B} 6 \hat{0}) \mathrm{F}_{1} q \times(129 q \times \mathrm{B} 6 \hat{0})$

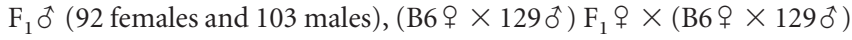
$\mathrm{F}_{1} \hat{\delta}$ (107 females and 91 males $)$, and $(\mathrm{B} 6 q \times 129 \hat{\jmath}) \mathrm{F}_{1} q \times(129 q \times$ B6 0 ) $\mathrm{F}_{1} \hat{0}$ (29 females and 34 males).

All $\mathrm{F}_{2}$ mice were tested in the two-bottle tests. When the two-bottle tests began, the $\mathrm{F}_{2}$ mice from group 1 were, on average, $2.20 \pm 0.02$ months old (with ages ranging from 2.0 to 3.0 months), and the $F_{2}$ mice from group 2 were, on average, $5.43 \pm 0.04$ months old (with ages ranging from 3.9 to 6.8 months). Mice from the parental B6 and 129 strains (10 females and 10 males for each strain; purchased from The Jackson Laboratory) received two-bottle tests simultaneously with the $\mathrm{F}_{2}$ mice from group 2 with the same stimuli, and the parental strain data were used to calculate heritability estimates. The B6 and 129 mice were $4.0 \pm$ 0.1 months old (ranging from 3.0 to 4.9 months) when the two-bottle tests began.

Electrophysiological experiments were conducted on 29 female and 29 male $\mathrm{F}_{2}$ mice from group 2; these mice represented all three reciprocal crosses. The $\mathrm{F}_{2}$ mice were selected for electrophysiological experiments to have similar numbers for each of three Tas1r3 genotypes (two homozygous and one heterozygous). Electrophysiological experiments were conducted when the mice were $9.3 \pm 0.1$ months old (ranging from 7.8 to 11.7 months).

Two-bottle tests. Construction of the drinking tubes and other experimental procedures have been described previously (Bachmanov et al., 2002a) and are given in detail on the Monell Mouse Taste Phenotyping Project web site (www.monell.org/MMTPP) (Tordoff and Bachmanov, 2001). Individually housed mice were presented with one tube containing a taste solution in deionized water and the other tube containing deionized water. Daily measurements were made in the middle of the light period by reading fluid volume to the nearest $0.1 \mathrm{ml}$.

During the first two test days, the $\mathrm{F}_{2}$ mice from group 1 received both tubes with deionized water. After that, they received taste solutions in the following order: 300 and $75 \mathrm{~mm} \mathrm{NaCl}, 120 \mathrm{~mm}$ sucrose, $0.1 \mathrm{~mm}$ citric acid, $10 \%$ ethanol (data not shown), and $0.03 \mathrm{~mm}$ quinine hydrochloride (Sigma, St. Louis, MO). The $\mathrm{F}_{2}$ mice from group 2, along with $\mathrm{B} 6$ and 129 mice, received taste solutions in the following order (in mM): 30 glycine, 30 D-phenylalanine, 20 and 1 saccharin, 120 and 300 sucrose, and 1 and 300 monosodium salt of L-glutamic acid (MSG) (Sigma). Each taste solution was presented for $4 \mathrm{~d}$ (this test duration provides optimal statistical power for detecting genetic differences) (Tordoff and Bachmanov, 2002). The positions of the tubes were switched every $24 \mathrm{hr}$ to control for positional preferences. Between the test series, mice were offered water to drink from both tubes for at least $2 \mathrm{~d}$ to offset any carry-over effects (with the exception that 300 and $75 \mathrm{~mm} \mathrm{NaCl}$ solutions were tested without a break in the first group and 120 and $300 \mathrm{~mm}$ sucrose solutions were tested without a break in the second group). Body weights were measured before and after each test series.

For each solution concentration, individual average solution and water intakes were calculated based on daily intake values. Preference ratios were calculated for each mouse as the ratio of the average daily solution intake to average daily total fluid (solution plus water) intake, in percentage.

Electrophysiology. Activity of the whole chorda tympani nerve in response to lingual application of taste solutions was electrophysiologically recorded in $58 \mathrm{~F}_{2}$ mice from group 2 . Techniques for surgery, taste stimulation, and recordings have been described previously (Inoue et al., 2001a,b). The following taste stimuli were used (in mM): 10, 30, 100, 300, and 1000 sucrose; $0.2,0.6,2,6$, and 20 saccharin; $1,3,10,30,100,300$, and 1000 glycine; 10, 30, 100, 300, and $1000 \mathrm{~L}$-alanine; 10, 100, and 500 L-proline; 10, 30, and $100 \mathrm{~L}$-glutamine; 10, 30, and $100 \mathrm{D}$-phenylalanine; 30 D-tryptophan; 0.1, 1, 3, 10, 100, 300, and 1000 MSG; 0.1, 0.3, 1, and 10 disodium salt of inosine $5^{\prime}$-monophosphate (IMP); a mixture of 0.3 IMP with 1,10 , and 100 MSG (this mixture was used to examine synergism between MSG and 5' -ribonucleotides) (Ninomiya et al., 1992); 0.1, 1, 10, and 100 monoammonium salt of L-glutamic acid ( $\mathrm{NH}_{4}$ glutamate); 0.1, $1,10,100$, and $1000 \mathrm{NaCl} ; 100 \mathrm{KCl} ; 2$ and 20 quinine hydrochloride; 10 $\mathrm{HCl} ; 100 \mathrm{NH}_{4} \mathrm{Cl}$ (Sigma); and 0.01, 0.1, and $1 \mathrm{SC}-45647$ (a gift from Dr. G. DuBois, The Coca-Cola Company, Atlanta, GA). The $100 \mathrm{~mm} \mathrm{NH}_{4} \mathrm{Cl}$ solution was presented at regular intervals to serve as a reference stimulus. During chemical stimulation of the tongue, the test solutions flowed for $30 \mathrm{sec}$. Between taste stimuli, the tongue was rinsed with deionized water for at least $1 \mathrm{~min}$.

The magnitude of the integrated response at $20 \mathrm{sec}$ after stimulus onset was measured and expressed as a proportion of the average of the previous and following responses to $100 \mathrm{~mm} \mathrm{NH}_{4} \mathrm{Cl}$. We chose $\mathrm{NH}_{4} \mathrm{Cl}$ as a standard stimulus for data correction to be consistent with our previous studies (Bachmanov et al., 1997; Inoue et al., 2001a,b; Li et al., 2001). Moreover, in our previous analyses (discussed in detail in Inoue et al., 2001a,b), we have shown that (1) $\mathrm{NH}_{4} \mathrm{Cl}$ responses normalized relative to responses to other taste stimuli are similar in the $\mathrm{B} 6$ and 129 strains, and (2) results of response normalization relative to $\mathrm{NH}_{4} \mathrm{Cl}$ are similar to normalization using an alternative approach proposed by Frank and Blizard (1999). An additional argument supporting the appropriateness of our standardization procedure is that in this study we observed genotypical differences in responses to only a subset of stimuli, rather than generalized differences that would be expected if they were confounded by the standardization procedure.

Genotyping. We genotyped markers polymorphic between the B6 and 129 strains. The markers represented microsatellites (D4Mit4, D4Mit7, D4Mit33, D4Mit42, D4Mit58, D4Mit190, D4Mit204, D4Mit209, D4Mit254, D4Mit256, D4Mit264, D4Mon1, and D4Smh6b), expressed sequence tags (D18346, D4Ertd296e, K00231, and M134G01), end sequences of bacterial artificial chromosome clones (118E21-SP6, 130A12SP6, 139J18-T7, 238O5-T7, 280G12-SP6, 280G12-T7, 338N4-SP6, 338N4-T7, 350D2-T7, 360M12-SP6, 387F5-SP6, 387F5-T7, 415A22-SP6, and 49O2-T7), and genes (Tas1r1, Tas1r3, Trp73, and V2r2). Information about these markers is available in the Mouse Genome Database (http://www.informatics.jax.org). Primer sequences can be found in the study by Li et al. (2002b). DNA purification and genotyping procedures have been described previously (Bachmanov et al., 2001b; Li et al., 2002b).

Data analyses. The phenotypical data were analyzed using Pearson correlation coefficients, Student's $t$ tests, ANOVA, and planned comparisons. Effects of the Tas1r3 genotype on behavioral and electrophysiological phenotypes were estimated using one-way ANOVA for each solution concentration. The analyses were conducted using STATISTICA software (StatSoft, Tulsa, OK).

Because of multiple comparisons, in our preliminary analyses we applied the Bonferroni correction to determine thresholds of statistical significance. Using the Bonferroni correction and using $p<0.01$ as the threshold for statistical significance yielded identical results. Therefore, for simplicity, we use here the $p<0.01$ criterion to report statistical significance, but we also indicate all effects significant at $p<0.05$. 
We did not find phenotypical differences between $\mathrm{F}_{2}$ mice from different reciprocal crosses; therefore, the data for mice from all reciprocal crosses were pooled. In some cases, behavioral or neural responses differed between $\mathrm{F}_{2}$ males and females, or between $\mathrm{F}_{2}$ mice from the two experimental groups. To offset these differences, we standardized data within each gender of each experimental group of the $\mathrm{F}_{2}$ mice to the group mean (0) and SD (1); the standardized data were used in linkage analysis.

Because taste solution intake can depend on body size or customary fluid consumption (Bachmanov et al., 2002a,b), we examined potential confounding effects of variation in body weight and water intake. We found no linkages to distal chromosome 4 for average body weight measured throughout the period of preference tests [the logarithm of the odds (LOD), $\leq 0.2$ ] or intakes of water given in both drinking tubes to $F_{2}$ mice from group 1 (LOD, $\leq 1.8) . \mathrm{F}_{2}$ mice with different Tas $1 \mathrm{r} 3$ genotypes had the following body weights [30.2 $\pm 0.5 \mathrm{gm}(129 / 129), 30.7 \pm 0.4 \mathrm{gm}$ (129/B6), and $30.6 \pm 0.5 \mathrm{gm}(\mathrm{B} 6 / \mathrm{B} 6)]$ and water intakes $[5.3 \pm 0.1 \mathrm{ml}$ (129/129), $5.1 \pm 0.1 \mathrm{ml}(129 / \mathrm{B} 6)$, and $4.8 \pm 0.1 \mathrm{ml}(\mathrm{B} 6 / \mathrm{B} 6)]$. This demonstrates that linkages of sweetener intakes to distal chromosome 4 are not confounded by variation in body weight and water intake, and we, therefore, analyzed raw intakes unadjusted for body size or customary fluid intake.

Heritability in the broad sense (the degree of genetic determination) was estimated based on variances in the parental strains and $F_{2}$. The environmental (nongenetic) variance was calculated as an average between the phenotypical (total) variances for the two parental strains: $\mathrm{VAR}_{\mathrm{E}}=1 / 2\left(\mathrm{VAR}_{\mathrm{B} 6}+\mathrm{VAR}_{129}\right)$. The genetic variance was calculated as a difference between the phenotypic variance of the $\mathrm{F}_{2}$ generation and the environmental variance: $\mathrm{VAR}_{\mathrm{G}}=\mathrm{VAR}_{\mathrm{F} 2}-\mathrm{VAR}_{\mathrm{E}}$. The heritability estimate was calculated as a percentage of the genetic variance from the phenotypical variance of $\mathrm{F}_{2}: \mathrm{h}^{2}=\mathrm{VAR}_{\mathrm{G}} / \mathrm{VAR}_{\mathrm{F} 2} \times 100$ (Wright, 1968; Falconer and Mackay, 1996). For solution intakes and preferences, heritability was calculated for males and females separately, and then the estimates for each gender were averaged. For chorda tympani responses, heritability was calculated from data for both genders pooled. Details on heritability calculations (Bachmanov et al., 2002c), some of the phenotypical data for the B6 and 129 strains used to estimate heritability (Bachmanov et al., 2000; Inoue et al., 2001a), and preliminary biometric analyses of preferences for some of the taste solutions in the $\mathrm{B} 6 \times 129 \mathrm{~F}_{2}$ mice (Bachmanov et al., 1996b; Bachmanov et al., 2000) have been published previously.

Interval mapping was conducted using MAPMAKER software (Lander et al., 1987) with phenotypical scores of the $\mathrm{F}_{2}$ mice standardized within each gender and experimental group. Although only data for chromosome 4 are presented here, they were obtained as a part of a whole genome screen. Therefore, genome-wide thresholds of significant (LOD, 4.3 ) and suggestive (LOD, 2.8) linkages for an $F_{2}$ intercross under an unconstrained (free) model were applied (Lander and Kruglyak, 1995). The confidence interval was defined as LOD score drops of 2.0 from the LOD peak. The percentage of phenotypical variance explained by linkages to distal chromosome 4 was determined using MAPMAKER/QTL output. Using this value and heritability estimates (described above), the percentage of genetic variance explained by linkages to distal chromosome 4 was calculated as: $\%$ of phenotypical variance explained/heritability $\times 100$.

To assess dominant/additive interactions between the Tas $1 r 3$ alleles, the phenotypical mean for the 129/B6 heterozygotes was compared with the collapsed phenotypical value for the 129/129 and B6/B6 homozygotes; this test was achieved using planned comparisons.

\section{Results}

A linkage map of chromosome 4 was constructed using MAPMAKER/EXP software based on genotypes of polymorphic genetic markers in the $\mathrm{F}_{2}$ mice. The order of the markers and linkage distances between them were: D4Mit264 - $20.0 \mathrm{cM}$ - D4Mit4 $15.8 \mathrm{cM}$ - D4Mit7 - $10.2 \mathrm{cM}$ - D4Mit58 - $22.5 \mathrm{cM}$ - D4Mit204 $20.2 \mathrm{cM}$-D4Mit33 - $1.5 \mathrm{cM}$ - D4Mit190 - $1.1 \mathrm{cM}$ - D4Mit42 - $0.2 \mathrm{cM}$ Tas1r1 - 0.9 cM - D4Mit254 - 0.1 cM - Trp73 - 0.6 cM - D4Mit209- 2.8

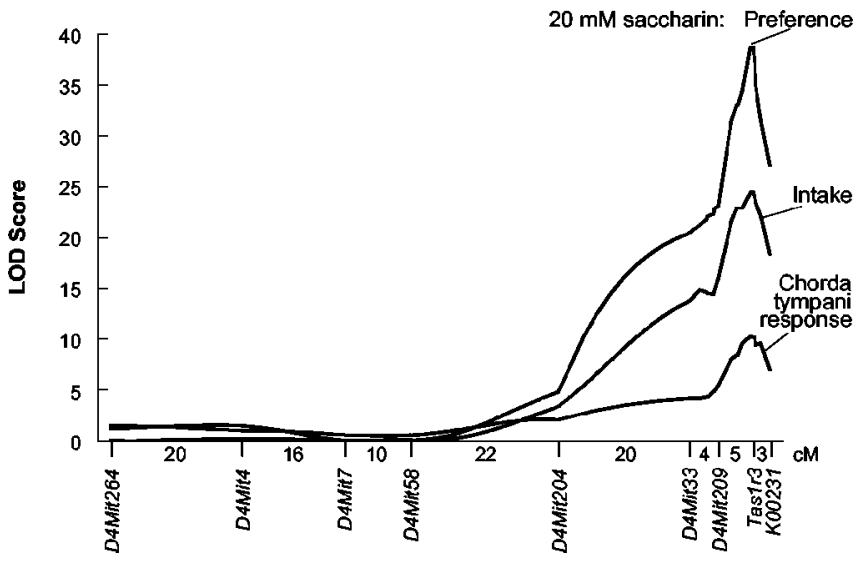

Figure 1. Chromosome 4 interval mapping of behavioral and neural responses to $20 \mathrm{~mm}$ saccharin. Distances between markers in centimorgans were estimated using MAPMAKER/EXP software and are shown below the $x$-axis. The curves trace the LOD scores for $20 \mathrm{~mm}$ saccharin preferences, intakes, and chorda tympani responses calculated under an unconstrained (free) model using MAPMAKER/QTL software.

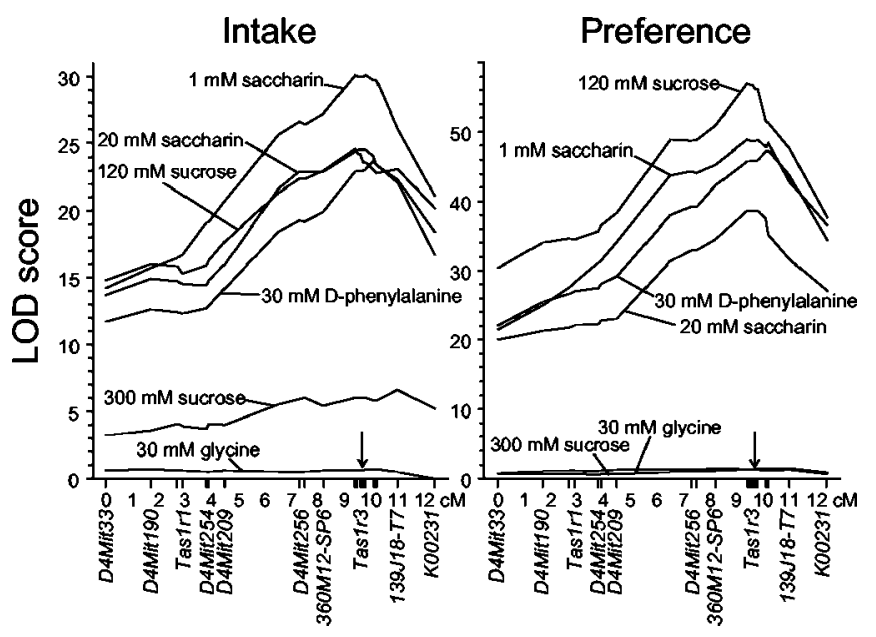

Figure 2. Distal chromosome 4 interval mapping of sweetener intakes (left) and preferences (right). Marks on the $x$-axis show marker positions. The arrows indicate a position of the Tas $1 r 3$ gene. Other explanations are the same as in Figure 1.

cM - D4Mit256 - 0.2 cM - D4Smh6b - 0.7 cM - (360M12-SP6, 415A22SP6 ) - 1.2 cM - 280G12-T7 - $0.1 \mathrm{cM}$ - (49O2-T7, 118E21-SP6, 387F5SP6, 338N4-T7) - $0.1 \mathrm{cM}-$ M134G01 - $0.1 \mathrm{cM}$ - (Tas1r3, D18346) - 0.1 cM - 350D2-T7- 0.3 cM - D4Mon1 - 0.1 cM - (130A12-SP6, 338N4-SP6, 387F5-T7,280G12-SP6 ) - 0.8 cM - 139J18-T7 - $1.4 \mathrm{cM}-$ K00231- $0.1 \mathrm{cM}$ - 238O5-T7 - $0.4 \mathrm{cM}$ - (V2r2, D4Ertd296e). There were no recombinations between markers shown in parentheses.

Next, associations between genotypes of chromosome 4 markers and quantitative phenotypical indices of behavioral and neural taste responses were analyzed using MAPMAKER/QTL software. For several sweeteners, both behavioral and neural responses were strongly linked to the distal (subtelomeric) region of chromosome 4. Examples of the whole chromosome 4 interval mapping for behavioral and neural responses to $20 \mathrm{~mm}$ saccharin are shown in Figure 1. Detailed linkage maps of the distal part of chromosome 4 are shown in Figures 2 (preferences and intakes) and 3 (chorda tympani responses).

For behavioral responses, significant (LOD, >4.3) linkages to distal chromosome 4 were found for $30 \mathrm{~mm}$ D-phenylalanine, 120 $\mathrm{mm}$ sucrose, and 1 and $20 \mathrm{~mm}$ saccharin intakes and preferences (Fig. 2). Intake of, but not preference for, $300 \mathrm{~mm}$ sucrose was 


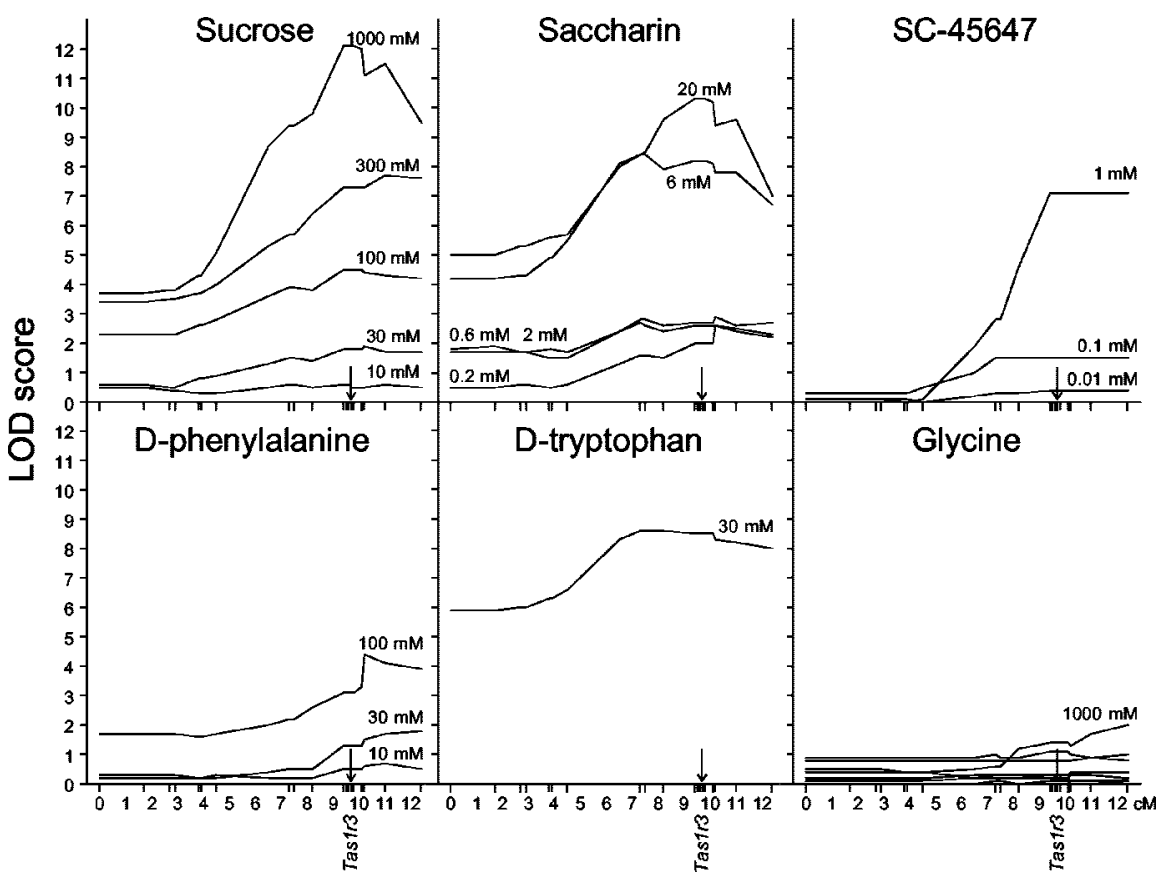

Figure 3. Distal chromosome 4 interval mapping of chorda tympani responses to six sweeteners. Explanations are the same as in Figure 2 .
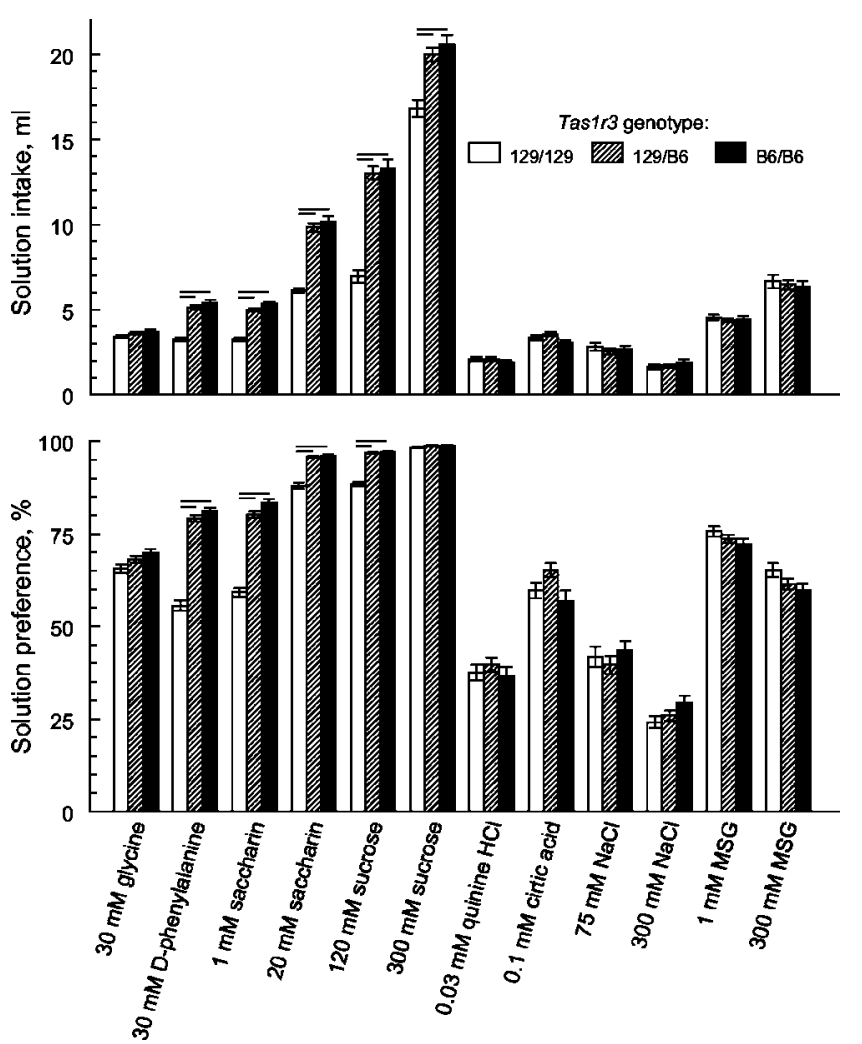

Figure 4. Taste solution intakes (top) and preference ratios (bottom) in $F_{2}$ mice with different Tas $1 r 3$ genotypes. Values are means $\pm \mathrm{SE}$. Horizontal bars indicate significant differences between groups ( $p<0.01$; planned comparisons; ANOVA).

also significantly linked to this region. No significant or suggestive linkages to distal chromosome 4 were found for behavioral responses to glycine (Fig. 2), quinine, citric acid, MSG, or $\mathrm{NaCl}$ (data not shown).
For chorda tympani activity, responses evoked by concentrated solutions of sucrose, saccharin, SC-45647, D-phenylalanine, and D-tryptophan were significantly linked to distal chromosome 4 (Fig. 3). No significant or suggestive linkages to distal chromosome 4 were found for chorda tympani responses to glycine (Fig. 3), L-alanine, L-proline, L-glutamine, quinine, $\mathrm{HCl}$, MSG, IMP, ammonium glutamate, $\mathrm{NaCl}$, $\mathrm{KCl}$, and 0.1-300 mM MSG (data not shown). Chorda tympani responses to the highest $(1 \mathrm{M})$ concentration of MSG were suggestively linked to distal chromosome 4 (LOD, 3.1; confidence interval spanning a region between D4Mit58 and the telomeric end).

The significant linkages to distal chromosome 4 explained $7-26 \%$ of phenotypical variation in sweetener intakes and $33-39 \%$ of phenotypical variation in preference ratios (Table 1 ). Heritability estimates were $48-86 \%$ for intakes and $34-61 \%$ for preferences. Based on the proportion of phenotypical variance explained by these loci and trait heritabilities, we estimated that these linkages accounted for $10-35 \%$ of genetic variance of intakes and $66-96 \%$ of genetic variance of preferences. The significant linkages to distal chromosome 4 explained $30-82 \%$ of phenotypical variation and $37-92 \%$ of genetic variation in chorda tympani responses to sweeteners, with heritabilities ranging from 75 to $95 \%$ (Table 2).

Confidence intervals for all significant linkages included the Tas1r3 gene and a small adjacent region (Figs. 1-3; Tables 1, 2). The Tas1r3 gene encoding the T1R3 taste receptor protein involved in transduction of sweet taste was discovered based on the genetic mapping of the saccharin preference ( $\mathrm{Sac}$ ) locus. Thus, the Tas1r3 gene most likely accounts for the linkages of the sweetener responses to distal chromosome 4 . We, therefore, have analyzed behavioral (Fig. 4) and neural (Fig. 5) taste responses of the $\mathrm{F}_{2}$ mice with different Tas1r3 genotypes.

Consistent with the interval mapping results, the Tas1r3 genotype of the $\mathrm{F}_{2}$ mice significantly affected $30 \mathrm{mM} \mathrm{D}$ phenylalanine, $120 \mathrm{~mm}$ sucrose, and 1 and $20 \mathrm{~mm}$ saccharin intakes and preferences $\left(F_{(2,451-619)}>56 ; p<0.000001\right.$; one-way ANOVAs). Intakes of (but not preferences for) $300 \mathrm{~mm}$ sucrose also depended on the Tas1r3 genotype $\left(F_{(2,449)}=14.2 ; p=0.00001\right)$. For all these responses, mice homozygous for the B6 allele of Tas $1 r 3$ and 129/B6 Tas1r3 heterozygotes had similar values that were higher than those of mice homozygous for the 129 allele of Tas1r3 (Fig. 4). In all these cases, the responses of the Tas1r3 heterozygotes were higher than the mean for the two homozygous genotypes $(p<0.02$; planned comparisons), which demonstrates dominance of the B6 allele of the Tas $1 r 3$ gene over its 129 allele. Associations of the Tas1r3 genotype with glycine preference or citric acid intake and preference were marginally significant ( $p=0.026-0.048$ ). Indexes of consumption of other solutions (quinine, $\mathrm{NaCl}$, and MSG) were similar in mice with different Tas1r3 genotypes.

The Tas1r3 genotype of the $\mathrm{F}_{2}$ mice significantly affected their chorda tympani responses to $100-1000 \mathrm{~mm}$ sucrose, $0.6-20 \mathrm{~mm}$ saccharin, $1 \mathrm{~mm}$ SC-45647, $100 \mathrm{~mm}$ D-phenylalanine, and $30 \mathrm{~mm}$ D-tryptophan (Figs. 5, 6) $\left(F_{(2,16-55)}>6.9 ; p<0.003\right.$; one-way ANOVA). Compared with the 129/129 homozygotes, the B6/B6 
Table 1. Significant linkages of solution intakes and preferences to distal chromosome 4

\begin{tabular}{|c|c|c|c|c|c|c|}
\hline Solution & Index & Peak LOD score & Confidence interval $^{a}$ & $\begin{array}{l}\text { Percentage of phenotypical } \\
\text { variance explained }\end{array}$ & Heritability & $\begin{array}{l}\text { Percentage of genetic } \\
\text { variance explained }^{b}\end{array}$ \\
\hline \multirow[t]{2}{*}{30 mm d-Phenylalanine } & Intake & 23.7 & 360M12-SP6-K00231 & 21 & 71 & 30 \\
\hline & Preference & 47.3 & 360M12-SP6-K00231 & 38 & 57 & 66 \\
\hline \multirow[t]{2}{*}{$1 \mathrm{~mm}$ Saccharin } & Intake & 30.1 & 360M12-SP6-139J18-T7 & 26 & 86 & 31 \\
\hline & Preference & 48.9 & 360M12-SP6-139J18-T7 & 39 & 61 & 64 \\
\hline \multirow[t]{2}{*}{20 mm Saccharin } & Intake & 24.5 & D4Mt209-139J18-T7 & 22 & 79 & 28 \\
\hline & Preference & 38.7 & 360M12-SP6- 130A12-SP6 & 33 & 34 & 95 \\
\hline \multirow[t]{2}{*}{120 mm Sucrose } & Intake & 24.6 & D4Smh6b-K00231 & 17 & 48 & 35 \\
\hline & Preference & 57.0 & 360M12-SP6-D4Mon1 & 35 & 36 & 96 \\
\hline $300 \mathrm{~mm}$ Sucrose & Intake & 6.6 & D4Mt209-telomeric end & 7 & 65 & 10 \\
\hline
\end{tabular}

${ }^{a}$ Confidence interval represents LOD score drops of 2.0 from the LOD peak.

${ }^{b}$ Proportion of genetic variance explained was calculated as: percentage of phenotypical variance explained/heritability $\times 100 \%$.

Table 2. Significant linkages of chorda tympani responses to distal chromosome 4

\begin{tabular}{|c|c|c|c|c|c|c|}
\hline Solution & Concentration (mм) & Peak LOD score & Confidence interval & $\begin{array}{l}\text { Percentage of phenotypical } \\
\text { variance explained }\end{array}$ & Heritability & $\begin{array}{l}\text { Percentage of genetic } \\
\text { variance explained }\end{array}$ \\
\hline \multirow[t]{3}{*}{ Sucrose } & 100 & 4.5 & Tas1r1 - telomeric end & 30 & 81 & 37 \\
\hline & 300 & 7.7 & D4Mt209 - telomeric end & 46 & 75 & 61 \\
\hline & 1000 & 12.1 & 360M12-SP6-K00231 & 62 & 86 & 72 \\
\hline \multirow[t]{2}{*}{ Saccharin } & 6 & 8.4 & D4Mt209- telomeric end & 49 & 82 & 59 \\
\hline & 20 & 10.3 & D4Mt209-K00231 & 57 & 95 & 60 \\
\hline SC-45647 & 1 & 7.1 & 360M12-SP6 - telomeric end & 82 & 89 & 92 \\
\hline D-Phenylalanine & 100 & 4.4 & D4Smh6b - telomeric end & 30 & $a$ & $a$ \\
\hline D-Tryptophan & 30 & 8.6 & Trp73 - telomeric end & 50 & 82 & 61 \\
\hline
\end{tabular}

Comments are the same as in Table 1.

${ }^{a}$ For D-phenylalanine, the nongenetic variance based on parental strain data was higher than the phenotypic variance in $F_{2}$ (probably because of sampling error), which precluded calculation of heritability and percentage of the genetic variance explained.

homozygotes had larger responses to these solutions. The responses in the 129/B6 heterozygotes were either similar to those of the B6/B6 homozygotes or intermediate between the B6/B6 and 129/129 homozygotes. The effect of the Tas1r3 genotype on responses to $0.2 \mathrm{~mm}$ saccharin, 10 and 500 $\mathrm{mM}$ L-proline, and $1000 \mathrm{~mm}$ MSG was marginally significant ( $p=0.015-0.029)$. Responses to glycine, L-alanine, L-glutamine, ammonium glutamate, IMP, and its combination with MSG, quinine, $\mathrm{HCl}$, and $\mathrm{KCl}$ were similar in mice with different Tas1r3 genotypes.

\section{Discussion}

We have shown that neural and behavioral gustatory responses to several sweeteners are linked to a region of distal chromosome 4 including the Tas1r3 ( Sac) gene. For solution intakes and preferences, significant linkages were found for sucrose, saccharin, and D-phenylalanine but not glycine. Chorda tympani responses to sucrose, saccharin, D-phenylalanine, D-tryptophan, and SC-45647, but not glycine, L-proline, L-alanine, or L-glutamine, were also significantly linked to this region. No linkages to distal chromosome 4 were detected for behavioral or neural responses to non-sweet quinine, citric acid, $\mathrm{HCl}, \mathrm{NaCl}, \mathrm{KCl}, \mathrm{MSG}$, IMP, and ammonium glutamate.

These results strongly indicate that all significant linkages for behavioral and neural responses to sweeteners are attributable to

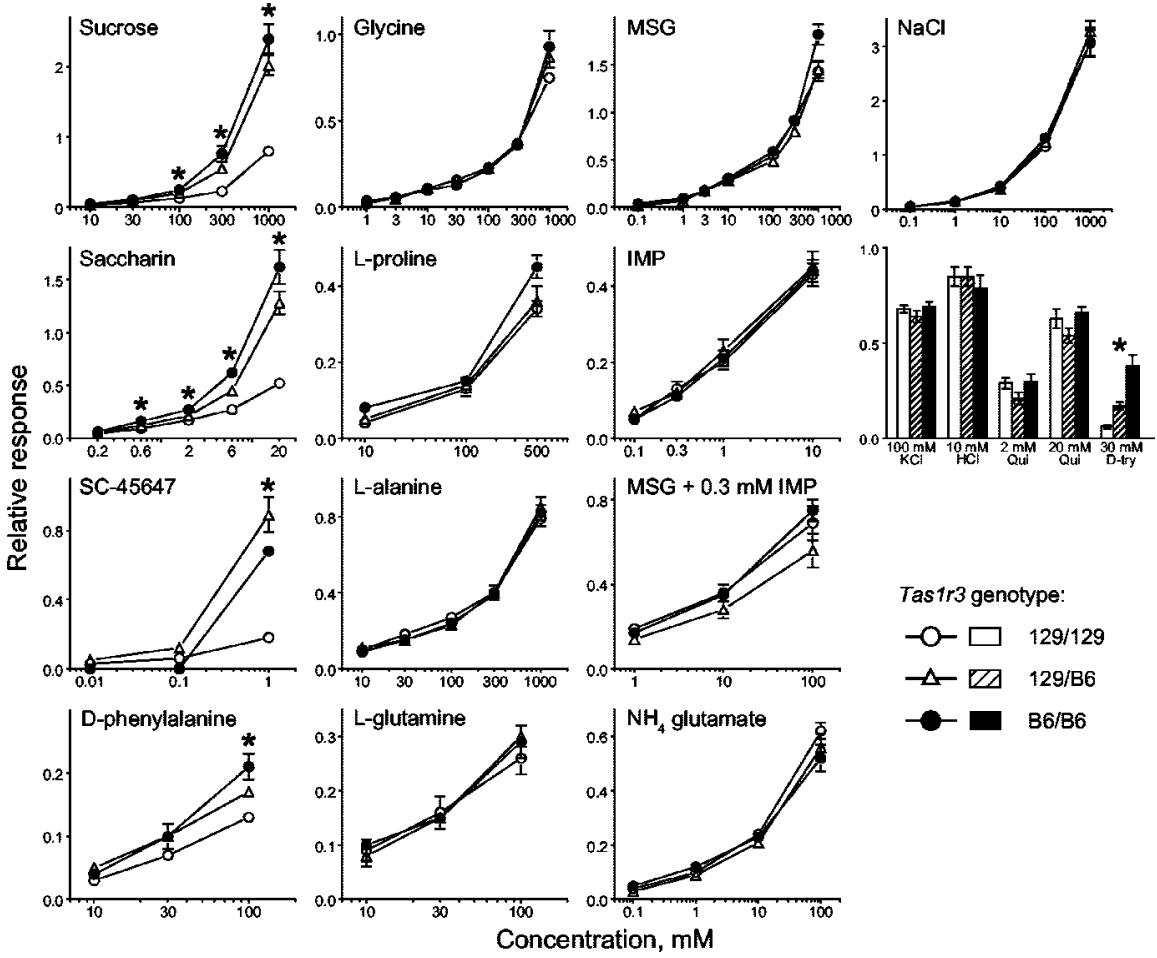

Figure 5. Chorda tympani responses (relative to $100 \mathrm{mM} \mathrm{NH}_{4} \mathrm{Cl}$ ) in $\mathrm{F}_{2}$ mice with different Tas $1 \mathrm{r} 3$ genotypes. Values are means \pm SE. Qui, Quinine hydrochloride; D-try, D-tryptophan. ${ }^{*} p<0.01$, effect of genotype; one-way ANOVA.

the pleiotropic effect of the same locus, rather than linkages to distinct loci in this region. First, for all linked traits, the B6 allele of this locus enhanced phenotypical values and was dominant or partially dominant. Second, the linkage statistic (LOD score) had a single peak, which was at the Tas $1 r 3$ locus. Third, annotation of 


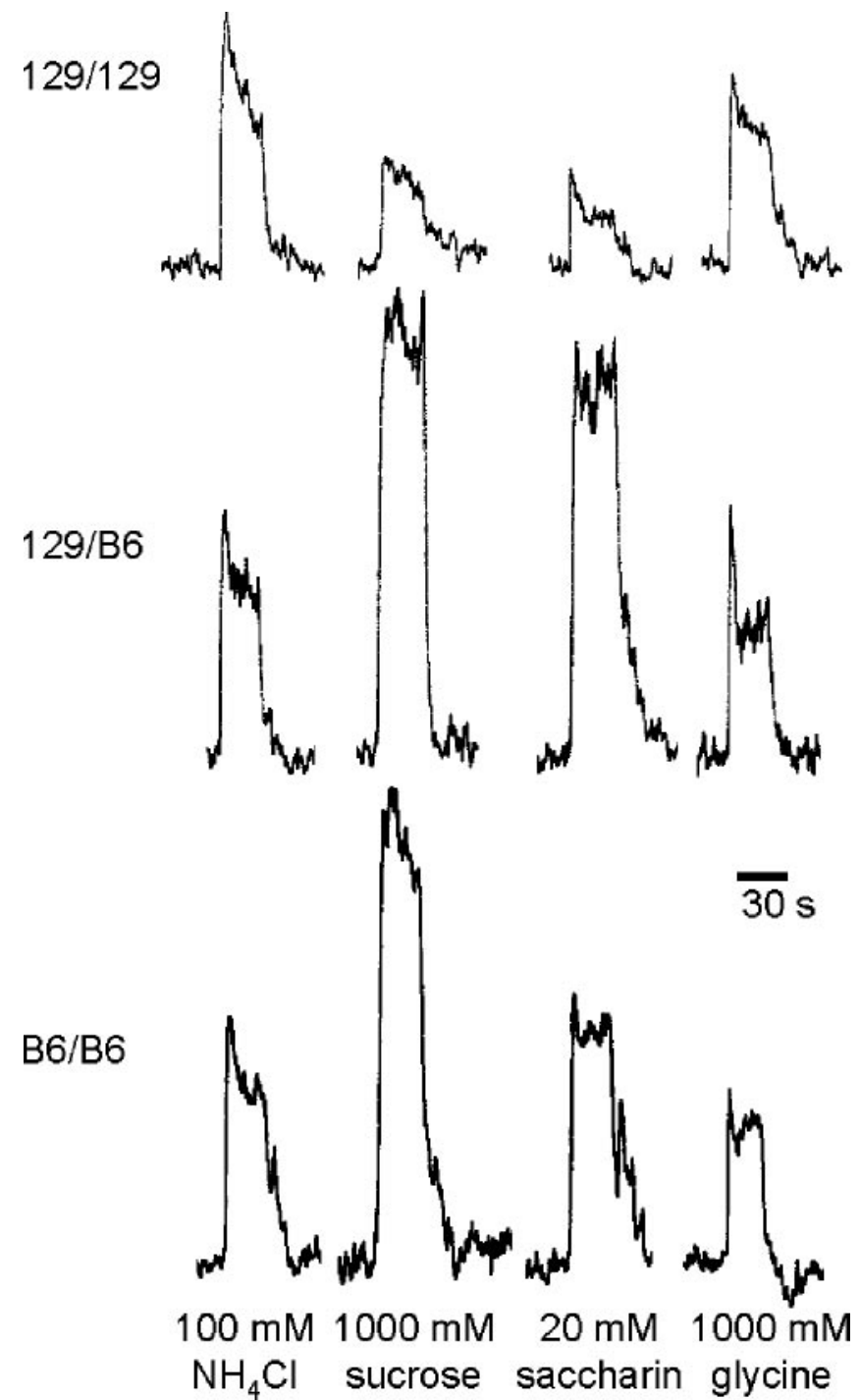

Figure 6. Sample recordings of integrated whole-nerve chorda tympani activity in three $\mathrm{F}_{2}$ mice with different Tas 133 genotypes: 129/129 (top), 129/B6 (middle), and B6/B6 (bottom). Responses in these mice relative to $100 \mathrm{~mm} \mathrm{NH}_{4} \mathrm{Cl}$ were, respectively: $1000 \mathrm{~mm}$ sucrose: 0.60 , 2.49, and 2.40; $20 \mathrm{~mm}$ saccharin: $0.33,2.11$, and $1.50 ; 1000 \mathrm{~mm}$ glycine: $0.84,0.59$, and 0.94 . Relative responses to sucrose and saccharin were higher in the Tas $1 \mathrm{r} 3 \mathrm{~B} 6$ homozygote and heterozygote compared with the 129/129 homozygote. Relative responses to glycine were similar in these mice.

distal chromosome 4 did not find any other genes near Tas1r3 that are known to be involved in taste (Bachmanov et al., 2001b; Li et al., 2002b). All this strongly suggests that that these linkages are attributed to allelic variation of the Tas1r3 gene encoding the T1R3 taste receptor protein.

Linkage results were generally consistent between behavioral and neural responses to the same taste stimuli. Both types of responses to sucrose, saccharin, and D-phenylalanine were linked to the Tas1r3 locus, and both types of responses to glycine, MSG, quinine, and $\mathrm{NaCl}$ were not significantly linked to this region. This fits into a model in which changes in properties of the T1R3 taste receptor protein affect afferent activity in sensory gustatory nerves evoked by a sweetener, which in turn influences consummatory behavior toward this sweetener.

Sequences of the Tas1r3 gene have multiple variants between the 129 and B6 strains, in both coding and in noncoding regions (Bachmanov et al., 2001b; Reed et al., 2004). Analysis of associa- tions between Tas1r3 sequences and saccharin preferences in 30 mouse strains identified eight candidate functional polymorphisms. Two of them resulted in amino acid substitutions; the rest were in noncoding regions or were silent polymorphisms. There were no differences in Tas1r3 gene expression in taste tissues of the B6 and 129 mice (Reed et al., 2004). This suggests that functional B6/129 allelic variants of Tas1r3 are likely to affect the ability of the T1R3 protein to form dimers or bind ligands. However, this hypothesis needs to be confirmed experimentally.

Although we recorded activity from only one of several afferent gustatory nerves (branches of VIIth, IXth and Xth cranial nerves) (Smith and Frank, 1993), the differences in chorda tympani responses are likely to be representative of activity in the other taste nerves. This is expected based on expression of the Tas1r3 gene in all types of taste papillae throughout the oral cavity (Kitagawa et al., 2001; Max et al., 2001; Montmayeur et al., 2001; Nelson et al., 2001; Sainz et al., 2001). Consistent with this, differences between B6 and 129 mice in responses to sweeteners were equivalent in the chorda tympani and glossopharyngeal nerves (M. Inoue, unpublished observations), which innervate different populations of taste papillae (Smith and Frank, 1993).

Studies involving conditioned taste aversion generalization and recording activity in single fibers of gustatory nerves (Ninomiya et al., 1984a,b; Kasahara et al., 1987; Ninomiya and Funakoshi, 1987) show that sweeteners used in this study have a similar, sucrose-like, taste quality to mice. Nevertheless, allelic variation of the taste receptor gene Tas $1 r 3$ affected responses to some, but not all, of these sweeteners. For example, behavioral and neural responses to glycine were not affected by Tas $1 r 3$ variation. This can be explained either by the existence of another sweet taste receptor binding glycine or by the action of glycine at a T1R3 receptor site that is not affected by the polymorphisms between the B6 and 129 strains. Glycine intakes and preferences were not linked to the Tas $1 r 3$ region in the $\mathrm{B} 6 \times 129 \mathrm{~F}_{2}$ hybrids, despite a difference between the parental B6 and 129 strains (Bachmanov et al., 2001a). This implies that the strain differences in glycine consumption depend on linkages to other genomic regions and is consistent with the possibility that an unknown receptor detecting the sweetness of glycine (and perhaps other compounds) is associated with these other linkages. Because all three known members of the Tas1r gene family cluster in distal chromosome 4 (Kitagawa et al., 2001; Li et al., 2001, 2002b; Montmayeur et al., 2001), the lack of linkage to this region for taste responses to glycine shows that none of the known T1R receptors are involved in the strain differences in glycine responsiveness.

Linkage to the Tas1r3 region explained a substantial fraction of genetic variation in responses to several sweeteners, sometimes $\sim 100 \%$ of it (e.g., for $20 \mathrm{~mm}$ saccharin and $120 \mathrm{~mm}$ sucrose preferences, and chorda tympani responses to $1 \mathrm{~mm} \mathrm{SC-45647)}$ (Tables 1,2). Compared with preference ratios, the portion of genetic variance in sweetener intakes attributed to this locus was lower $(\leq \sim 1 / 3)$, indicating a larger contribution of loci other than Tas1r3 to variation in sweetener intakes. Several other lines of evidence also suggest that behavioral responses to sweeteners depend on genes other than Tas1r3. These involve multigenic inheritance of sweetener consumption shown in several studies (Ramirez and Fuller, 1976; Phillips et al., 1994; Capeless and Whitney, 1995; Lush et al., 1995; Bachmanov et al., 1996b), the linkage of sweet taste responses to the $d p a$ locus on proximal chromosome 4 (Ninomiya et al., 1987, 1991; Capeless and Whitney, 1995; Bachmanov et al., 1997), and linkages for sweetener consumption detected in our genome scan of the B6 $\times 129$ inter- 
cross (A. A. Bachmanov, unpublished observations). These other genes may be involved in peripheral taste transduction or central mechanisms of ingestive behavioral responses.

The strength of linkage to the Tas1r3 region (both LOD scores and percentage of variance explained) varied depending on the sweetener solution concentration. For example, compared with behavioral responses to $120 \mathrm{~mm}$ sucrose, linkage of $300 \mathrm{~mm}$ sucrose intake was much weaker, and preference scores for this solution were unlinked to this region. The $300 \mathrm{~mm}$ sucrose solution evokes $\sim 100 \%$ preference in all mice regardless of the genotype (Fig. 4). We, thus, suspect that a ceiling effect prevents detection of any differences in $300 \mathrm{~mm}$ sucrose preferences. A smaller fraction of genetic variation explained by the Tas $1 r 3$ genotype for $300 \mathrm{~mm}$ sucrose intake compared with $120 \mathrm{~mm}$ sucrose intake suggests that as the concentration of sucrose increases, the relative contribution of peripheral taste responsiveness to its consumption decreases. Factors that may become more prominent in determining genetic variation in consumption of concentrated solutions of sucrose (and, to some degree, other sweeteners) may include central motivational mechanisms activated by sweet taste, postingestive rewarding properties of energy derived from sucrose, stimulation of gastrointestinal osmoreceptors, or the ability to excrete the large volumes of fluid consumed. For neural responses, linkages became stronger with increases in stimulus concentration, which may reflect a rise in the signal-to-noise ratio of the neural recordings.

B6 mice consume more MSG and IMP than do 129 mice (Bachmanov et al., 2000), but the responses of the B6 gustatory nerves to umami-tasting compounds are similar to, or slightly lower than, those of the 129 mice (Inoue, unpublished observations). Because it was suggested that umami-tasting compounds can activate components of sweet taste transduction in rodents (Yamamoto et al., 1991; Stapleton et al., 2002) and that the T1R3 protein is involved in transduction of both sweet and umami tastes (Li et al., 2002a), we examined whether responses to umami taste stimuli are associated with B6/129 allelic variants of the Tas $1 r 3$ gene. Our results show that the Tas1r3 allelic variants that influenced taste responses to several sweeteners did not significantly affect taste responses to umami stimuli. The only marginally significant effect of the Tas1r3 genotype was on chorda tympani responses to the highest $(1 \mathrm{M})$ concentration of MSG. This effect could either be a false positive (expected for these number of comparisons and the level of significance) or it may represent nonselective activation of sweet-responsive chorda tympani fibers by concentrated MSG. Although in our study B6/129 Tas1r3 allelic variation did not significantly affect behavioral or neural responses to umami taste stimuli, complete disruption of the Tas1r3 gene diminished them (Damak et al., 2003; Zhao et al., 2003). Thus, although the T1R3 receptor is involved in transduction of umami taste, the B6/129 sequence variants affecting its sensitivity to sweeteners do not affect its sensitivity to umami compounds.

Finally, our data demonstrate that the in vivo approach can be used to understand the function and specificity of taste receptors and to validate the findings of in vitro studies. Experiments involving expression of taste receptors in heterologous systems (Nelson et al., 2001, 2002; Li et al., 2002a) require substantial modification of the conditions that exist in vivo. This, for example, includes modification of receptors to traffic them to the cell membrane, using variable components of intracellular transduction, and an absence of regulatory influences existing in vivo. Thus, the in vivo and in vitro approaches complement each other in providing conclusive characteristics of taste receptors.

\section{References}

Bachmanov AA, Tordoff MG, Beauchamp GK (1996a) Ethanol consumption and taste preferences in C57BL/6ByJ and 129/J mice. Alcohol Clin Exp Res 20:201-206.

Bachmanov AA, Reed DR, Tordoff MG, Price RA, Beauchamp GK (1996b) Intake of ethanol, sodium chloride, sucrose, citric acid, and quinine hydrochloride solutions by mice: a genetic analysis. Behav Genet 26:563-573.

Bachmanov AA, Reed DR, Ninomiya Y, Inoue M, Tordoff MG, Price RA, Beauchamp GK (1997) Sucrose consumption in mice: major influence of two genetic loci affecting peripheral sensory responses. Mamm Genome 8:545-548.

Bachmanov AA, Tordoff MG, Beauchamp GK (2000) Intake of umamitasting solutions by mice: a genetic analysis. J Nutr 130:935S-941S.

Bachmanov AA, Tordoff MG, Beauchamp GK (2001a) Sweetener preference of C57BL/6ByJ and 129P3/J mice. Chem Senses 26:905-913.

Bachmanov AA, Li X, Reed DR, Ohmen JD, Li S, Chen Z, Tordoff MG, de Jong PJ, Wu C, West DB, Chatterjee A, Ross DA, Beauchamp GK (2001b) Positional cloning of the mouse saccharin preference ( $\mathrm{Sac}$ ) locus. Chem Senses 26:925-933.

Bachmanov AA, Reed DR, Beauchamp GK, Tordoff MG (2002a) Food intake, water intake, and drinking spout side preference of 28 mouse strains. Behav Genet 32:435-443.

Bachmanov AA, Beauchamp GK, Tordoff MG (2002b) Voluntary consumption of $\mathrm{NaCl}, \mathrm{KCl}, \mathrm{CaCl}_{2}$ and $\mathrm{NH}_{4} \mathrm{Cl}$ solutions by 28 mouse strains. Behav Genet 32:445-457.

Bachmanov AA, Reed DR, Li X, Li S, Beauchamp GK, Tordoff MG (2002c) Voluntary ethanol consumption by mice: genome-wide analysis of quantitative trait loci and their interactions in a C57BL/6ByJ $\times 129 \mathrm{P} 3 / \mathrm{J} \mathrm{F} 2$ intercross. Genome Res 12:1257-1268.

Blizard DA, Kotlus B, Frank ME (1999) Quantitative trait loci associated with short-term intake of sucrose, saccharin and quinine solutions in laboratory mice. Chem Senses 24:373-385.

Capeless CG, Whitney G (1995) The genetic basis of preference for sweet substances among inbred strains of mice: preference ratio phenotypes and the alleles of the Sac and dpa loci. Chem Senses 20:291-298.

Damak S, Rong M, Yasumatsu K, Kokrashvili Z, Varadarajan V, Zou S, Jiang P, Ninomiya Y, Margolskee RF (2003) Detection of sweet and umami taste in the absence of taste receptor T1r3. Science 301:850-853.

Danilova V, Hellekant G (2003) Comparison of the responses of the chorda tympani and glossopharyngeal nerves to taste stimuli in C57BL/6J mice. BMC Neurosci 4:5.

Falconer DS, Mackay TFC (1996) Introduction to quantitative genetics, Ed 4. Essex, UK: Longman.

Frank ME, Blizard DA (1999) Chorda tympani responses in two inbred strains of mice with different taste preferences. Physiol Behav 67:287-297.

Inoue M, McCaughey SA, Bachmanov AA, Beauchamp GK (2001a) Wholenerve chorda tympani responses to sweeteners in $\mathrm{C} 57 \mathrm{BL} / 6 \mathrm{ByJ}$ and 129P3/J mice. Chem Senses 26:915-923.

Inoue M, Li X, McCaughey SA, Beauchamp GK, Bachmanov AA (2001b) Soa genotype selectively affects mouse gustatory neural responses to sucrose octaacetate. Physiol Genomics 5:181-186.

Kasahara T, Iwasaki K, Sato M (1987) Taste effectiveness of some D- and L-amino acids in mice. Physiol Behav 39:619-624.

Kitagawa M, Kusakabe Y, Miura H, Ninomiya Y, Hino A (2001) Molecular genetic identification of a candidate receptor gene for sweet taste. Biochem Biophys Res Commun 283:236-242.

Lander ES, Kruglyak L (1995) Genetic dissection of complex traits: guidelines for interpreting and reporting linkage findings. Nat Genet 11:241-247.

Lander ES, Green P, Abrahamson J, Barlow A, Daly MJ, Lincoln SE, Newburg L (1987) MAPMAKER: an interactive computer package for constructing primary genetic linkage maps of experimental and natural populations. Genomics 1:174-181.

Li X, Inoue M, Reed DR, Huque T, Puchalski RB, Tordoff MG, Ninomiya Y, Beauchamp GK, Bachmanov AA (2001) High-resolution genetic mapping of the saccharin preference locus $(\mathrm{Sac})$ and the putative sweet taste receptor (T1R1) gene (Gpr70) to mouse distal chromosome 4. Mamm Genome 12:13-16.

Li X, Staszewski L, Xu H, Durick K, Zoller M, Adler E (2002a) Human receptors for sweet and umami taste. Proc Natl Acad Sci USA 99:46924696. 
Li X, Bachmanov AA, Li S, Chen Z, Tordoff MG, Beauchamp GK, de Jong PJ, Wu C, Chen L, West DB, Ross DA, Ohmen JD, Reed DR (2002b) Genetic, physical and comparative map of the subtelomeric region of mouse chromosome 4. Mamm Genome 13:5-19.

Lush IE (1989) The genetics of tasting in mice. VI. Saccharin, acesulfame, dulcin and sucrose. Genet Res 53:95-99.

Lush IE, Hornigold N, King P, Stoye JP (1995) The genetics of tasting in mice. VII. Glycine revisited, and the chromosomal location of Sac and Soa. Genet Res 66:167-174.

Max M, Shanker YG, Huang L, Rong M, Liu Z, Campagne F, Weinstein H, Damak S, Margolskee RF (2001) Tas1r3, encoding a new candidate taste receptor, is allelic to the sweet responsiveness locus Sac. Nat Genet 28:58-63.

Montmayeur JP, Liberles SD, Matsunami H, Buck LB (2001) A candidate taste receptor gene near a sweet taste locus. Nat Neurosci 4:492-498.

Nelson G, Hoon MA, Chandrashekar J, Zhang Y, Ryba NJ, Zuker CS (2001) Mammalian sweet taste receptors. Cell 106:381-390.

Nelson G, Chandrashekar J, Hoon MA, Feng L, Zhao G, Ryba NJ, Zuker CS (2002) An amino-acid taste receptor. Nature 416:199-202.

Ninomiya Y, Funakoshi M (1987) Qualitative discrimination among "umami" and four basic taste substances in mice. In: Umami: a basic taste (Kawamura Y, Kare MR, eds), pp 365-385. New York: Marcel Dekker.

Ninomiya Y, Mizukoshi T, Higashi T, Katsukawa H, Funakoshi M (1984a) Gustatory neural responses in three different strains of mice. Brain Res 302:305-314.

Ninomiya Y, Higashi T, Katsukawa H, Mizukoshi T, Funakoshi M (1984b) Qualitative discrimination of gustatory stimuli in three different strains of mice. Brain Res 322:83-92.

Ninomiya Y, Higashi T, Mizukoshi T, Funakoshi M (1987) Genetics of the ability to perceive sweetness of D-phenylalanine in mice. Ann NY Acad Sci 510:527-529.

Ninomiya Y, Sako N, Katsukawa H, Funakoshi M (1991) Taste receptor mechanisms influenced by a gene on chromosome 4 in mice. In: Genetics of perception and communication (Wysocki CJ, Kare MR, eds), pp 267278. New York: Marcel Dekker.

Ninomiya Y, Kurenuma S, Nomura T, Uebayashi H, Kawamura H (1992)
Taste synergism between monosodium glutamate and 5 '-ribonucleotide in mice. Comp Biochem Physiol A 101:97-102.

Ninomiya Y, Kajiura H, Mochizuki K (1993) Differential taste responses of mouse chorda tympani and glossopharyngeal nerves to sugars and amino acids. Neurosci Lett 163:197-200.

Phillips TJ, Crabbe JC, Metten P, Belknap JK (1994) Localization of genes affecting alcohol drinking in mice. Alcohol Clin Exp Res 18:931-941.

Ramirez I, Fuller JL (1976) Genetic influence on water and sweetened water consumption in mice. Physiol Behav 16:163-168.

Reed DR, Li S, Li X, Huang L, Tordoff MG, Starling-Roney R, Taniguchi K, West DB, Ohmen JD, Beauchamp GK, Bachmanov AA（2004） Polymorphisms in the taste receptor gene (Tas1r3) region are associated with saccharin preference in 30 mouse strains. J Neurosci 24:938-946.

Sainz E, Korley JN, Battey JF, Sullivan SL (2001) Identification of a novel member of the T1R family of putative taste receptors. J Neurochem 77:896-903.

Smith DV, Frank ME (1993) Sensory coding by peripheral taste fibers. In: Mechanisms of taste transduction (Simin SA, Roper SD, eds), pp 295338. Boca Raton, FL: CRC.

Stapleton JR, Luellig M, Roper SD, Delay ER (2002) Discrimination between the tastes of sucrose and monosodium glutamate in rats. Chem Senses 27:375-382.

Tordoff MG, Bachmanov AA (2001) Monell Mouse Taste Phenotyping Project. www. monell. org/MMTPP.

Tordoff MG, Bachmanov AA (2002) Influence of test duration on the sensitivity of the two-bottle choice test. Chem Senses 27:759-768.

Wright S (1968) Evolution and the genetics of populations, Vol 1, Genetics and biometrical foundations. Chicago: University of Chicago.

Yamamoto T, Matsuo R, Fujimoto Y, Fukanaga I, Miyasaka A, Imoto T (1991) Electrophysiological and behavioral studies on the taste of umami substances in the rat. Physiol Behav 49:919-925.

Zhao GQ, Zhang Y, Hoon MA, Chandrashekar J, Erlenbach I, Ryba NJ, Zuker CS (2003) The receptors for mammalian sweet and umami taste. Cell $115: 255-266$ 